\title{
Asymmetric Modelling and Control of an Electronic Throttle
}

\author{
Gisela Pujol*, Yolanda Vidal $^{1}$, Leonardo Acho ${ }^{1}$, Alessandro N. Vargas ${ }^{2}$ \\ 1 CoDAlab (Control, Dynamics and Applications), Departament de Matemàtica Aplicada III, Universitat Politècnica de \\ Catalunya, Barcelona, Spain. \\ ${ }^{2}$ Universidade Tecnololigica Federal do Parana, UTFPR, Electrotechnical Department, Paraná, Brasil.
}

\begin{abstract}
SUMMARY
This paper presents an improved model for an automotive electronic throttle inspired on the behavior observed in real-time experiments. Due to a number of issues, particularly the return-spring, the performance of the throttle valve depends on whether it is opening or closing. This asymmetric behavior was taken into account to design a mathematical model of the throttle body and to derive a nonlinear asymmetric PI controller. The experimental demonstration suggests that considering an asymmetric term dramatically improves the performance of the controller. Copyright (c) 2014 John Wiley \& Sons, Ltd.
\end{abstract}

Received ...

KEY WORDS: throttle; modelling; nonlinear control; experimental; parameter estimation.

\section{INTRODUCTION}

In fuel-injected engines, a throttle is a valve that regulates the amount of air entering the engine, which indirectly controls the power or speed of the engine [1]. Up until the late 1980s, most cars had a mechanical throttle body that was mechanically linked to the accelerator. However, today, almost all cars use electronic throttle control (ETC), which is referred to as drive-by-wire [2]. ETC uses electronic, rather than mechanical, signals to control the throttle. As the Engine Management System (EMS) of modern vehicle relies heavily on the performance of this servomechanism, the underlying control system must be efficient, robust and easily tunable. ETC system has a direct current (DC) motor that manipulates the throttle valve and a sensor to measure the throttle position. The return-spring restores the throttle to the so-called limp-home position in the case of a power supply failure [3] (see Fig. 1). From a control viewpoint, this problem seems to be a simple one of controlling a low-powered DC servo drive to position the throttle plate. However, a number of issues make the application of the control principle a little more difficult, especially in a massproduction context, such as friction, limp-home nonlinearity and parameter dispersion, among others $[4,5,6,7,8,9,10]$. Also, throttle modelling and identification is a hard issue due to these nonlinear phenomena [11], but for control design, simplified models for a throttle body can be considered $[12,13]$.

Some important topics of the throttle valve, particularly the return-spring, show that its behavior depends on whether it is opening or closing. This asymmetric performance is considered here to model the throttle body and to derive a nonlinear asymmetric PI controller. These two issues

\footnotetext{
*Correspondence to: CoDAlab, Departament de Matemàtica Aplicada III, Universitat Politècnica de Catalunya BarcelonaTECH, Terrassa, Colom 1, 08222 Spain. E-mail: gisela.pujol@upc.edu

Contract/grant sponsor: Spanish Ministry of Economy and Competitiveness: DPI2012-32375/FEDER, DPI201125822 and DPI2011-28033-C03-01; Government of Catalonia (Spain): 2014SGR859; Brazilian agencies CAPES 88881.030423/2013-01 and CNPq 248470/2013-02.
} 

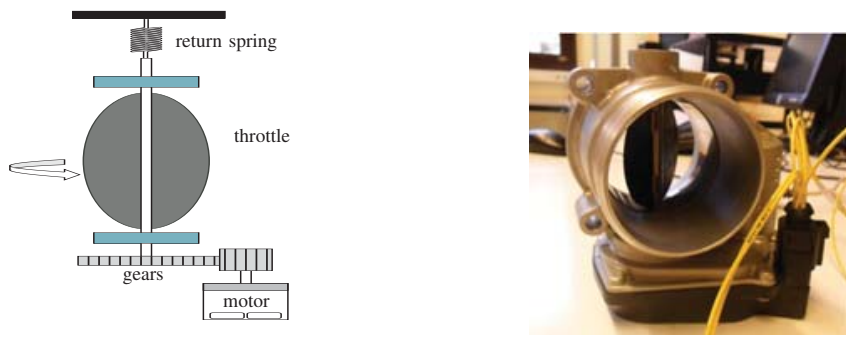

Figure 1. Left: throttle schematic. Right: automotive electronic throttle body used in experimental validation.

Table I. Definition of variables and constants.

\begin{tabular}{ll}
\hline Variable & Definition \\
\hline $\mathrm{x}_{1}(t)$ & Throttle angle position \\
$\mathrm{J}$ & Rotary inertia of motor \\
$\mathrm{K}_{s}$ & Spring constant \\
$\mathrm{K}_{d}$ & Viscous damping constant \\
$\mathrm{K}_{f}$ & Coulomb friction constant \\
$\mathrm{K}_{T}$ & Torque constant \\
$\mathrm{u}(\mathrm{t})$ & Voltage supplied \\
\hline
\end{tabular}

(modeling and control design) represent the main contribution of this paper. In addition, we implemented and checked the control rule in a laboratory experimental environment that includes a real throttle (a Continental VDO electronic throttle body, Model A2C59511705, P.N. 06F13306J, used in many vehicles). We referred this setup to as a Hardware-in-the-Loop (HiL) demonstration, as in [7].

This paper is structured as follows. Section 2 describes the proposed throttle modelling and the HiL test platform. Section 3 derives the asymmetric PI controller. The HiL testing results are presented in Section 4. Finally, Section 5 states the conclusions.

\section{MODELLING AND OFF-LINE PARAMETER ESTIMATION}

In order to introduce the notation, a well-known model of the throttle body is recalled. Based on this simple model, in the sequence we propose an improved model which takes into account an observed asymmetric behavior of the throttle body.

The relationship between the valve plate position $x_{1}(t)$ and the angular velocity of the rotor is $x$. ${ }_{1}(t)=b x_{2}(t)$, where $b$ is a parameter that depends on the throttle gears [14]. The throttle dynamics can now be expressed by summing up the moments about the throttle shaft $[15,16,17]$. There are four main moments acting upon the shaft, as follows. The moment from the return spring, the viscous and Coulomb friction moments, and the moment applied by the electric motor:

$$
J \dot{x}_{2}(t)=-K_{s} x_{1}(t)-K_{d} x_{2}(t)-K_{f} \operatorname{sgn}\left(x_{2}(t)\right)+K_{T} u(t),
$$

where Table I defines the variables and constants in (1). Thus, the mathematical model of the throttle body in the state space is given by:

$$
\begin{aligned}
& \dot{x}_{1}(t)=b x_{2}(t), \\
& \dot{x}_{2}(t)=-a_{1} x_{1}(t)-a_{2} x_{2}(t)-a_{3} \operatorname{sgn}\left(x_{2}(t)\right)+a_{4} u(t),
\end{aligned}
$$

with $a_{1}=\frac{K_{s}}{J}, a_{2}=\frac{K_{d}}{J}, a_{3}=\frac{K_{f}}{J}$, and $a_{4}=\frac{K_{T}}{J}$.

\subsection{Experimental Study}

The HiL test platform [7], shown in Fig. 2, is mounted with the following components: 


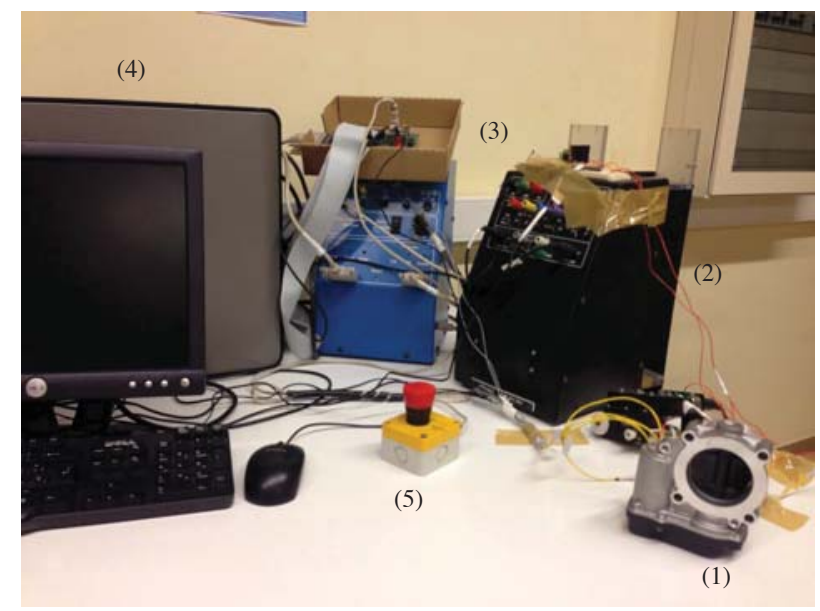

Figure 2. Experimental setup for the electronic throttle control: (1) Throttle, (2) Power unit, (3) Quanser, (4) Matlab/Simulink, (5) Security STOP button.

- A Quanser Q4 real-time control board (to integrate the experimental setup with Matlab/Simulink);

- A Quanser UPM180-25-B-PWM power amplifier (to supply the voltage and electrical current consumed by the equipment);

- A Continental VDO electronic throttle body, Model A2C59511705, P.N. 06F13306J, used in many vehicles. The throttle device is equipped with two position sensors, mainly for security reasons and redundant control. In the proposed experimental setup, only one sensor is used.

In order to estimate the throttle angular velocity, the velocity estimator $\frac{s}{0.01 s+1}$ is used [18]. This proposed velocity estimator has also been used in [19] adding a low-pass filter to obtain velocity estimates from position measurements.

\subsection{Verification of the asymmetric behavior}

To study the behavior of the system described in Eq. (2), we consider a standard proportional control law, which stabilizes the system without requiring knowledge about the servomechanism parameters. The control objective is to follow a reference position, $x_{1_{\text {ref }}}(t)$ :

$$
u(t)=-K_{p} \underbrace{\left(x_{1}(t)-x_{1_{r e f}}(t)\right)}_{\epsilon(t)} .
$$

The proportional gain, $K_{p}$, is tuned online. Fig. 3 shows the experimental performance of the proportional control described in Eq. (3). It can be observed that the performance of the throttle valve depends heavily on whether it is opening or closing. This is justified by the fact that the returnspring is dissipating energy when the throttle valve is on its way back to its limp-home position. We can observe in Fig. 3 that when going downstairs the overshoots are bigger than upstairs. The returnspring has a kind of influence on the parameter $K_{d}$ stated in equation (1). We propose a modified mathematical model that takes into account this kind of asymmetric behavior:

$$
\begin{aligned}
\dot{x}_{1}(t)= & b x_{2}(t), \\
\dot{x}_{2}(t)= & -a_{1} x_{1}(t)-a_{2_{+}}\left(\frac{1+\operatorname{sgn}\left(x_{2}\right)}{2}\right) x_{2}(t) \\
& \quad-a_{2-}\left(\frac{1-\operatorname{sgn}\left(x_{2}\right)}{2}\right) x_{2}(t)-a_{3} \operatorname{sgn}\left(x_{2}(t)\right)+a_{4} u(t) .
\end{aligned}
$$

When $a_{2_{+}}=a_{2_{-}}$, Eq. (4) retrieves Eq. (2). As we will see in Section 3, the asymmetry will also be used to design what we have referred to as an asymmetric PI controller. 


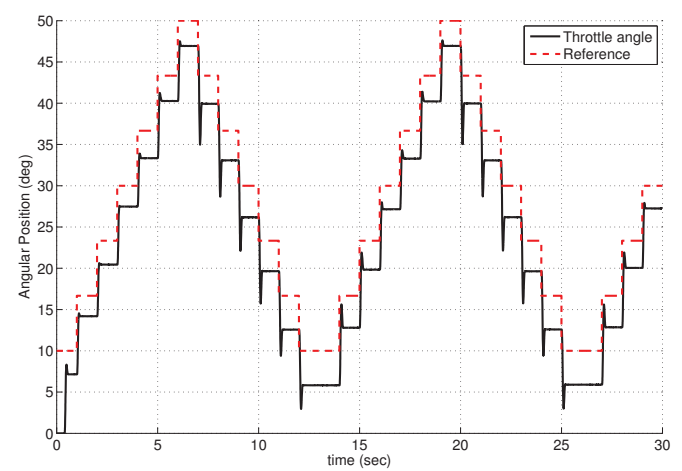

Figure 3. Experimental results: the reference signal, $x_{1_{\text {ref }}}(t)$, and the throttle position, $x_{1}(t)$, using the proportional control law described in Eq. (3), with $K_{p}=27$.

\subsection{Parameter Estimation}

Now we present the methodology which was used to estimate the parameters of the throttle model given in Eq. (4). Using the adaptive parameter identification method presented in [20], we estimate these parameters using a persistent excitation (PE), presented in Fig. 4, that is rich enough to excite all of their modes as required for estimate all the parameters [21, 20]. The goal is to select an appropriate PE signal. According to ([22]-Chap. 8), for linear systems, the convergent estimation of $\mathrm{m}$ parameters requires at least ${ }^{m}$ sigusoids on the input excitation signal. Although our model is nonlinear (4), it approaches to a linear system when $x_{2}$ is positive and to another one when $x_{2}$ is negative. Thus, in our estimation scheme, we use it to realize an excitation signal containing three sinusoid terms (shown in Fig. 4).

The closed loop system described in Eq. (3)-(4) is written as:

$$
\begin{aligned}
& \dot{x}_{1}(t)= b x_{2}(t), \\
& \dot{x}_{2}(t)=-\underbrace{\left(a_{1}+K_{p} a_{4}\right)}_{A_{1}} x_{1}(t)-a_{2+}\left(\frac{1+\operatorname{sgn}\left(x_{2}\right)}{2}\right) x_{2}(t) \\
& \quad-a_{2_{-}}\left(\frac{1-\operatorname{sgn}\left(x_{2}\right)}{2}\right) x_{2}(t)-a_{3} \operatorname{sgn}\left(x_{2}(t)\right)+\underbrace{K_{p} a_{4}}_{A_{4}} x_{1_{\text {ref }}}(t) .
\end{aligned}
$$

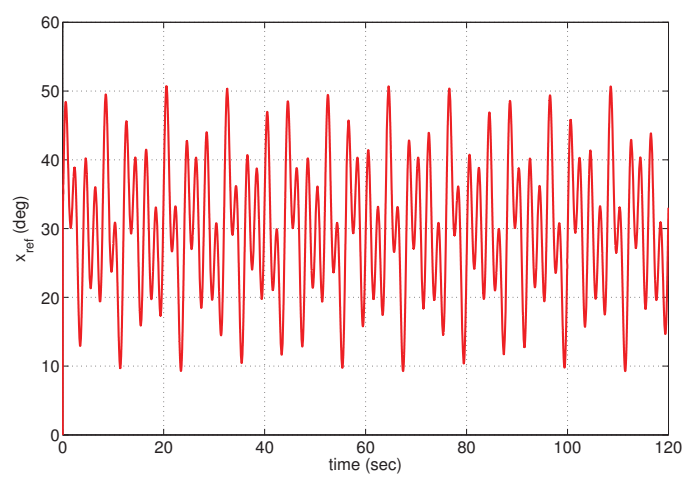

Figure 4. Persistent excitation $x_{1_{\text {ref }}}(t)$ used for parameter estimation.

The estimated parameters of $\left\{b, A_{1}, a_{2+}, a_{2-}, a_{3}, A_{4}\right\}$ are defined by $\hat{b}, \hat{A}_{1}(t), \hat{a}_{2_{+}}(t), \hat{a}_{2_{-}}(t)$, $\hat{a}_{3}(t)$ and $\hat{A}_{4}(t)$, respectively. The auxiliar state variable is $\left(\hat{x}_{1}(t), \hat{x}_{2}(t)\right)$. The parameter estimator 
Table II. The control and system parameters.

\begin{tabular}{lll}
\hline Parameter & Identified Value & Units \\
\hline$K_{p}$ & 27 & - \\
$b$ & 0.004 & - \\
$a_{1}$ & 0.03 & $\mathrm{~s}^{-2}$ \\
$a_{2_{+}}$ & 0.08 & $\mathrm{~s}^{-1}$ \\
$a_{2_{-}}$ & 0.06 & $\mathrm{~s}^{-1}$ \\
$a_{3}$ & 0.28 & $\mathrm{rad} / \mathrm{s}^{2}$ \\
$a_{4}$ & 0.001 & $\mathrm{rad} / V \mathrm{~s}^{2}$ \\
\hline
\end{tabular}

[20] is defined as:

$$
\begin{aligned}
& \dot{\hat{x}}_{1}(t)=\hat{b} x_{2}(t)-\lambda\left(\hat{x}_{1}(t)-x_{1}(t)\right), \\
& \dot{\hat{b}}(t)=-\sigma \hat{b}(t)-\gamma\left(\hat{x}_{1}(t)-x_{1}(t)\right) x_{2}(t), \\
& \dot{\hat{x}}_{2}(t)=\left(\hat{A}_{1}(t) \hat{a}_{2_{+}}(t) \hat{a}_{2_{-}}(t) \hat{a}_{3}(t) \hat{A}_{4}(t)\right)\left(\begin{array}{c}
-x_{1}(t) \\
-\frac{1+\operatorname{sgn}\left(x_{2}\right)}{2} x_{2}(t) \\
-\frac{1-\operatorname{sgn}\left(x_{2}\right)}{2} x_{2}(t) \\
-\operatorname{sgn}\left(x_{2}(t)\right) \\
x_{1_{\text {ref }}}(t)
\end{array}\right) \\
& -\lambda\left(\hat{x}_{2}(t)-x_{2}(t)\right) .
\end{aligned}
$$

The adaptive laws are given by:

$$
\begin{aligned}
& \dot{\hat{\hat{A}}}_{1}(t)=-\sigma \hat{A}_{1}(t)-\gamma\left(\hat{x}_{2}(t)-x_{2}(t)\right) x_{1}(t), \\
& \dot{\hat{a}}_{2_{+}}(t)=-\sigma \hat{a}_{2_{+}}(t)-\gamma\left(\hat{x}_{2}(t)-x_{2}(t)\right) \frac{1+\operatorname{sgn}\left(x_{2}\right)}{2} x_{2}(t), \\
& \dot{\hat{a}}_{2_{-}}(t)=-\sigma \hat{a}_{2_{-}}(t)-\gamma\left(\hat{x}_{2}(t)-x_{2}(t)\right) \frac{1-\operatorname{sgn}\left(x_{2}\right)}{2} x_{2}(t), \\
& \dot{\hat{a}}_{3}(t)=-\sigma \hat{a}_{3}(t)-\gamma\left(\hat{x}_{2}(t)-x_{2}(t)\right) \operatorname{sgn}\left(x_{2}(t)\right), \\
& \dot{\hat{A}}_{4}(t)=-\sigma \hat{A}_{4}(t)-\gamma\left(\hat{x}_{2}(t)-x_{2}(t)\right) x_{1_{\text {ref }}}(t) .
\end{aligned}
$$

where $\lambda$ and $\gamma$ are positive design numbers to be specified. To stabilize the parameter identification scheme (6)-(7) and to solve the drift parameter problem [22], a linear term is added in the dynamics, using the well-known $\sigma$-modification technique, see $[23,24]$ and references therein.

Table II presents the estimated parameter values (considering $\lambda=1, \gamma=0.1$ and $\sigma=0.1$ ). It is noteworthy that parameters $a_{2}$ and $a_{2}$ tend to different values, thus showing the asymmetric behavior of the throttle body and the proposed model (4). Fig. 4 plots the reference signal $x_{1_{\text {ref }}}(t)$, whereas Fig. 5 and 6 show the time history plots of estimated system parameters.

At this respect, our proposed model is a simple one but captured the asymmetric behavior. Fig. 7 plots the performance of the proposed model (4) with the estimated parameters in Table II, $\mathrm{i} \mathrm{n}$ front of the real experimental setup, showing an acceptable behavior. Moreover, by comparing the experimental validation of the model used in [4] and [5] with ours, we can appreciate that the error between the model and the experimental response is smaller in our case (error approximatively reduced by $10 \%)$.

\section{ASYMMETRIC PI CONTROL}

\subsection{Definition}

It is well-known that Proportional Integral (PI) control can assure closed-loop stability without requiring knowledge of the servomechanism parameters $[25,26,27,28,29]$. We propose a 


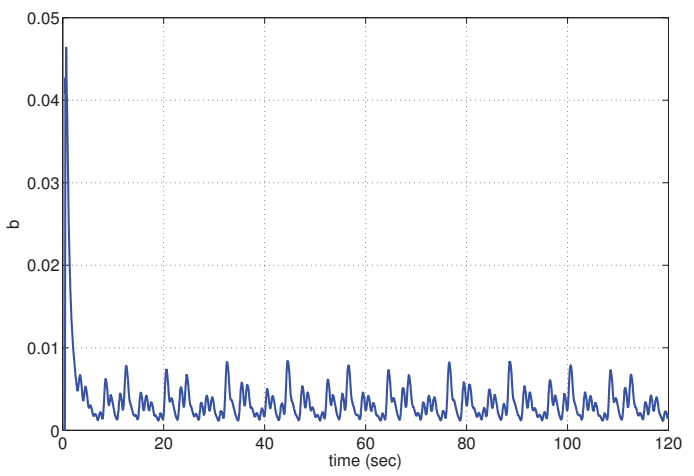

Figure 5. Time response of estimated parameter $b$.
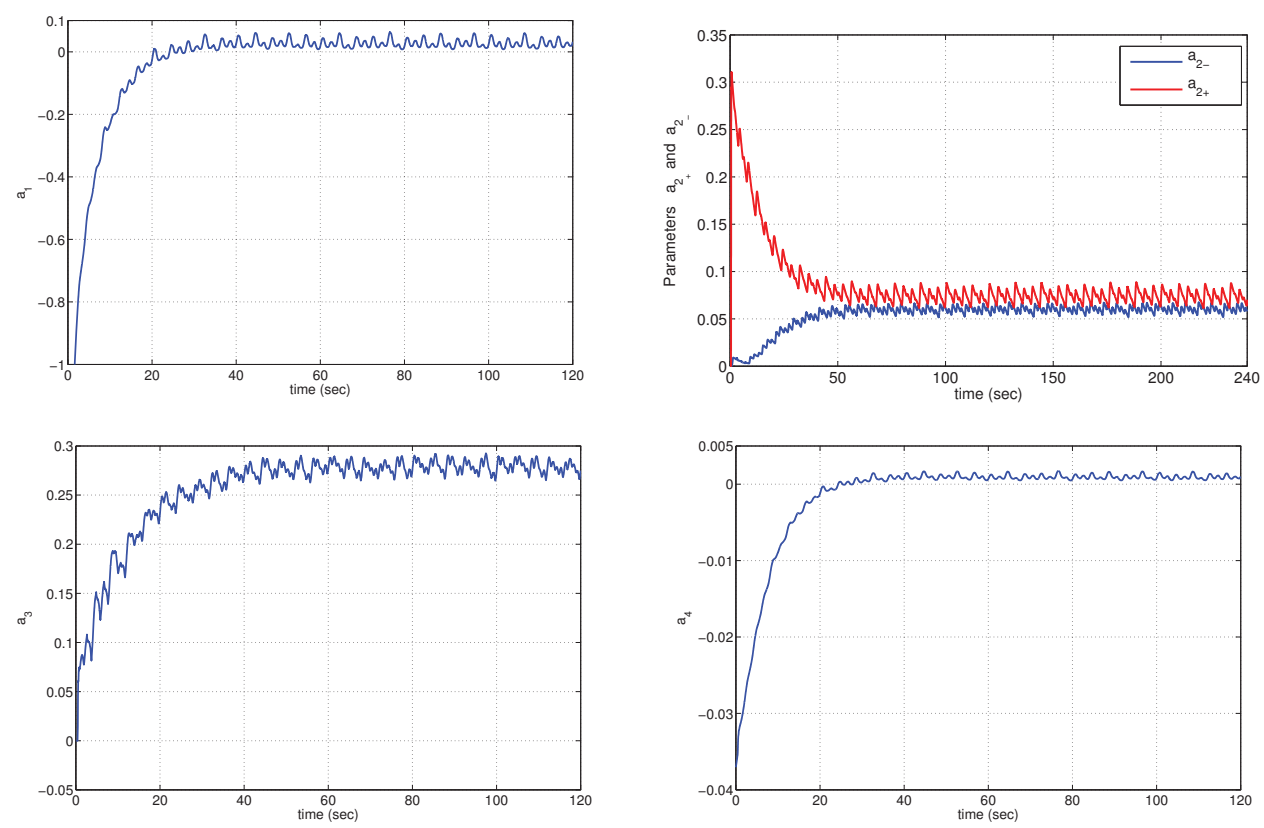

Figure 6. Time response of estimated parameters $a_{1}, a_{2_{+}}, a_{2_{-}}, a_{3}$, and $a_{4}$.

modification of the standard PI controller as follows. The main idea is to account in the controller the asymmetric property observed in the throttle mechanism. For this purpose, a nonlinear asymmetric PI controller is defined as follows:

$$
\left\{\begin{array}{l}
u(t)=-K_{p} \epsilon(t)-k\left(x_{2}(t)\right) \int_{0}^{t} \epsilon(\tau) d \tau ; \quad \epsilon(t)=x_{1}(t)-x_{1_{\text {ref }}}, \\
k\left(x_{2}(t)\right)=K_{1}\left(\frac{1+\operatorname{sgn}\left(x_{2}\right)}{2}\right)+K_{2}\left(\frac{1-\operatorname{sgn}\left(x_{2}\right)}{2}\right)
\end{array}\right.
$$

where $x_{1_{\text {ref }}}$ is assumed constant and the control parameters, $K_{p}, K_{1}$ and $K_{2}$, are tuned on-line. Note that when $K_{1}=K_{2}$, a standard PI controller is obtained.

It follows immediately form (4) and (8) that the controlled asymmetric system reads as: 


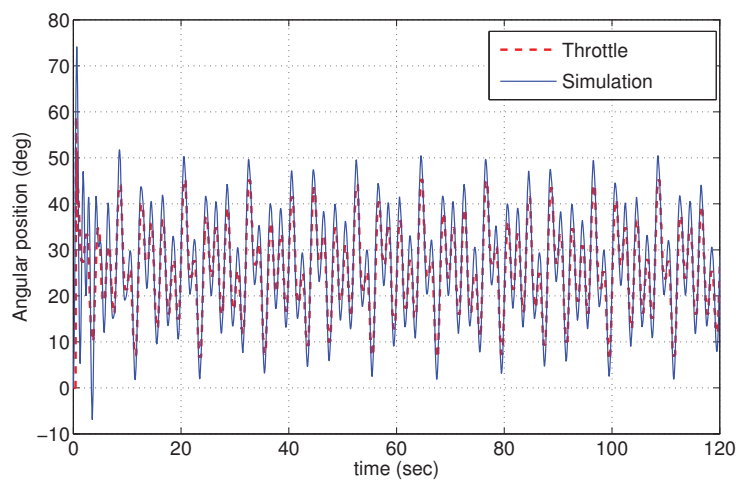

Figure 7. Comparison of the proposed mathematical model with the estimated parameters versus the experimental setup.

- When $x_{2}(t)>0$ :

$$
\begin{aligned}
& \dot{x}_{1}(t)=b x_{2}(t), \\
& \dot{x}_{2}(t)=-a_{1} x_{1}(t)-a_{2+} x_{2}(t)-a_{3}-a_{4} K_{p}\left(x_{1}(t)-x_{1_{\text {ref }}}\right)-a_{4} K_{1} \int_{0}^{t}\left(x_{1}(\tau)-x_{1_{\text {ref }}}\right) d \tau .
\end{aligned}
$$

- When $x_{2}(t)<0$ :

$$
\begin{aligned}
& \dot{x}_{1}(t)=b x_{2}(t), \\
& \dot{x}_{2}(t)=-a_{1} x_{1}(t)-a_{2-} x_{2}(t)+a_{3}-a_{4} K_{p}\left(x_{1}(t)-x_{1_{\text {ref }}}\right)-a_{4} K_{2} \int_{0}^{t}\left(x_{1}(\tau)-x_{1_{\text {ref }}}\right) d \tau .
\end{aligned}
$$

\subsection{Stability analysis}

Our control objective consists on proving that the closed-loop system (9)-(10) satisfies:

$$
\lim _{t \rightarrow \infty}\left(x_{1}(t)-x_{1_{\text {ref }}}\right)=0,
$$

and

$$
\lim _{t \rightarrow \infty} x_{2}(t)=0 .
$$

Defining the error vector as $e(t)=\left(e_{1}(t), e_{2}(t), e_{3}(t)\right)^{T}$, where:

$$
\begin{aligned}
& e_{1}(t)=x_{1}(t)-x_{1_{\text {ref }}}, \\
& e_{2}(t)=\dot{e}_{1}(t) \\
& e_{3}(t)=\dot{e}_{2}(t)=b \dot{x}_{2}(t)
\end{aligned}
$$

the closed-loop system (9)-(10) has the following representation:

$$
\dot{e}(t)=f(t)= \begin{cases}f_{1}(t) & e_{2}>0 \\ f_{2}(t) & e_{2}<0,\end{cases}
$$

where

$$
f_{1}(e(t))=\left(\begin{array}{ccc}
0 & 1 & 0 \\
0 & 0 & 1 \\
-b K_{1} a_{4} & -b\left(a_{1}+a_{4} K_{p}\right) & -a_{2_{+}}
\end{array}\right) e(t)
$$


and

$$
f_{2}(e(t))=\left(\begin{array}{ccc}
0 & 1 & 0 \\
0 & 0 & 1 \\
-b K_{2} a_{4} & -b\left(a_{1}+a_{4} K_{p}\right) & -a_{2-}
\end{array}\right) e(t) .
$$

Formally, we can define the switching surface as $s_{w}\left(e_{2}\right)=\left\{e_{2}=0\right\}$. According to Filippov's theory [30], a vector solution $e(t)$ to (11) is said to exist if it is absolutely continuous on $[0, \infty)$, and for almost all $t \in[0, \infty)$,

$$
\dot{e} \in C\left[f_{1}, f_{2}\right](e),
$$

where $C\left[f_{1}, f_{2}\right]$ denotes the convex closure over all sets of measure zero. Also, using Filippov's theory, system (11) with (12)-(13) is said to be quadratically stable if there exists a positive definite matrix $P=P^{T}>0$, such that for $V(e(t))=e^{T}(t) P e(t)$, the following conditions hold [31]:

(i) $e(t) \in \mathbf{R}^{3}-\left\{e_{2}=0\right\}: \dot{V}(e(t))=\frac{\partial V(e)}{\partial e} \dot{e}(t)<0$.

(ii) $e(t) \in\left\{e_{2}=0\right\}: \sup _{\alpha \in[0,1]} \frac{\partial V(e(t))}{e}\left(\alpha f_{1}(e(t))+(1-\alpha) f_{2}(e(t))\right)<0$.

Using (11), condition $(i)$ reduces to the following linear matrix inequality (LMI):

$$
\dot{V}(e)=e^{T} P f_{i} e+e^{T} f_{i}^{T} P e<0 \Leftrightarrow P f_{i}+f_{i}^{T} P<0, i=1,2 .
$$

Condition (14) defines a first restriction on design control parameters $K_{p}, K_{1}$ and $K_{2}$. Employing now $e_{2}=0$, condition $(i i)$ reduces to:

$$
\sup _{\alpha \in[0,1]}\left(A(\alpha) e_{1}^{2}+B(\alpha) e_{1} e_{3}+C(\alpha) e_{3}^{2}\right)<0,
$$

where

$$
\begin{aligned}
& A(\alpha)=p_{13}\left(\alpha f_{11}+(1-\alpha) f_{31}\right), \\
& B(\alpha)=p_{12}+p_{33}\left(f_{11} \alpha+(1-\alpha) f_{12}\right)+p_{13}\left(f_{31} \alpha+(1-\alpha) f_{32}\right), \\
& C(\alpha)=p_{23}+p_{33}\left(f_{31} \alpha+(1-\alpha) f_{32}\right), \\
& f_{11}=-b K_{1} a_{4}, \\
& f_{12}=-b K_{2} a_{4}, \\
& f_{31}=-a_{2_{+}}, \\
& f_{32}=-a_{2_{-}} .
\end{aligned}
$$

To conclude the quadratic stability of the closed-loop system (4)-(8), control design parameters $K_{p}$, $K_{1}$ and $K_{2}$ have to be choose verifying (14) and (15). Then, the control objectives will be satisfied.

\section{HIL TESTING}

The HiL testing shows that the asymmetric PI controller $\left(K_{1} \neq K_{2}\right)$ outperforms the standard PI controller, as observed in Fig. 8 and 9 for a triangular reference signal. For a precise comparison, we consider the index performance $J_{e}$ :

$$
J_{e}(t)=\int_{0}^{t}|\epsilon(\tau)| d \tau
$$

where $t$ is the total time of the experiment. In practice, we consider the control under three different cases, as follows:

- Case 1: $K_{1}<K_{2}\left(K_{1}=13, K_{2}=17\right)$;

- Case 2: $K_{1}=K_{2}\left(K_{1}=K_{2}=15\right.$ : standard PI); 
- Case 3: $K_{1}>K_{2}\left(K_{1}=20, K_{2}=10\right)$.

Note that these values $K_{1}$ and $K_{2}$, with $K_{p}=27$, verify the stability conditions (14) and (15), as shown in appendix.

To evaluate controller performance, two groups of experiments are done, one using a triangular reference command and the other employing sinusoidal signal. The experimental data obtained from the HiL testing indicates that the asymmetric PI controller outperforms the standard PI. In particular, for these references, case $3\left(K_{1}>K_{2}\right)$ generates the best experimental performance from the system response. Fig. 8 to 10 plot the performance using triangular reference, and Fig. 12-13 sinusoidal reference. The hysteresis profile is shown in Fig. 11 for the triangular reference signal.

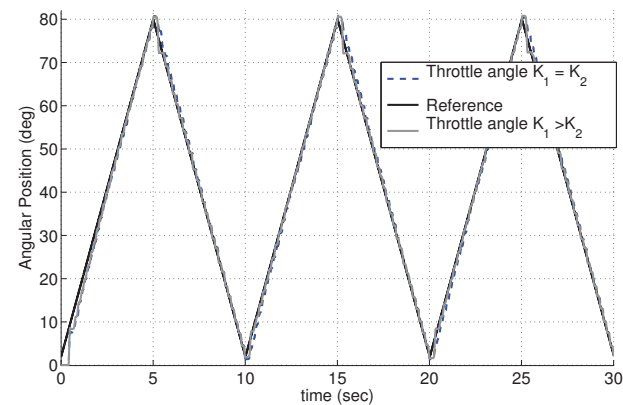

Figure 8. Reference and throttle position for Cases 1, 2 and 3.

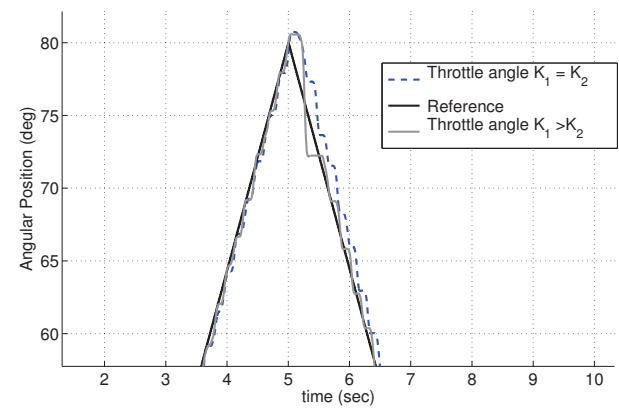

Figure 9. Zoom of Fig. 8.

\section{CONCLUSIONS}

The main contribution of this work is to propose a mathematical model for the throttle body, a largely used automotive device, and the model is able to incorporate an asymmetric behavior observed in practice. An improved PI controller that takes into account this asymmetry is derived. According to the HiL experiments, the proposed asymmetric PI controller is robust against unmodeled nonlinearities and friction phenomena. Even while the controller was designed under the assumption of constant reference, according to experiments, the proposed controller is able to follow "slow-time varying" reference signals. 


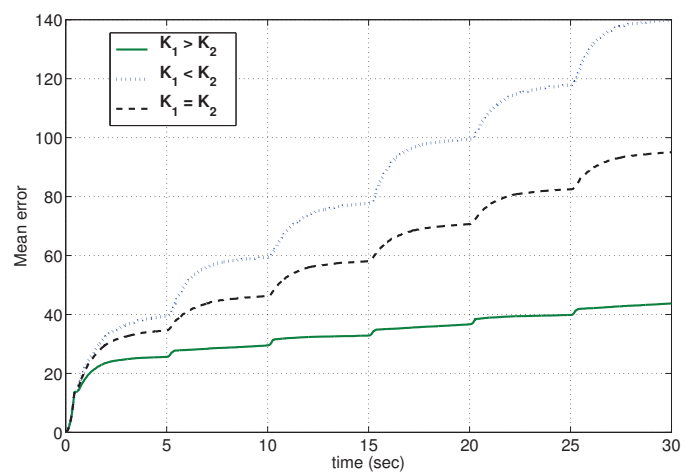

Figure 10. Time evolution of performance index $J_{e}$ for the triangular reference signal. Cases 1,2 and $3 .$.

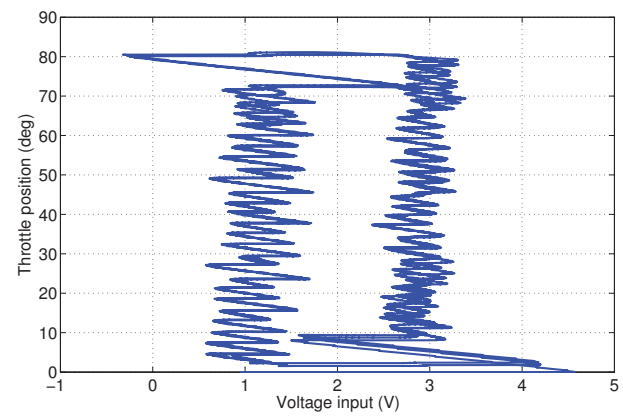

Figure 11. Hysteretic profile for the triangular reference signal.

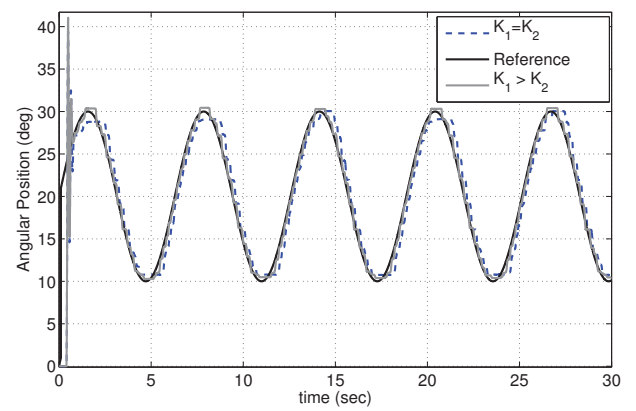

Figure 12. Reference and throttle position for Cases 1, 2 and 3.

\section{APPENDIX}

In this appendix we verify stability conditions (14) and (15) for each experimental case, as detailed in Section 4:

- Case 1: $K_{1}<K_{2}\left(K_{1}=13, K_{2}=17\right)$;

- Case 2: $K_{1}=K_{2}\left(K_{1}=K_{2}=15\right.$ : standard PI $)$;

- Case 3: $K_{1}>K_{2}\left(K_{1}=20, K_{2}=10\right)$.

Solving condition (14) for each case, we obtain: 


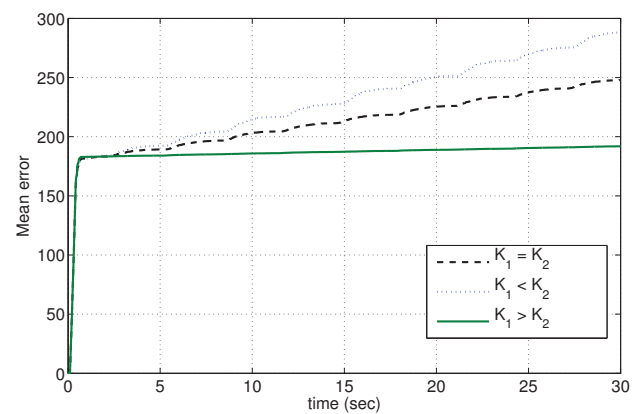

Figure 13. Time evolution of performance index $J_{e}$ for the sinusoidal reference signal. Cases 1, 2 and 3.

- Case 1:

$$
P_{1}=\left(\begin{array}{ccc}
0.000003038256658 & -0.000030740292589 & 0.003494163567980 \\
-0.000030740292589 & 0.000488388252668 & -0.033390809683919 \\
0.003494163567980 & -0.033390809683919 & 4.381308815351976
\end{array}\right)
$$

- Case 2:

$$
P_{2}=\left(\begin{array}{ccc}
0.000000010992354 & -0.000000103274934 & 0.000013795037474 \\
-0.000000103274934 & 0.000001101284704 & -0.000128368898903 \\
0.000013795037474 & -0.000128368898903 & 0.017655632705306
\end{array}\right)
$$

- Case 3:

$$
P_{3}=\left(\begin{array}{ccc}
0.000000343658323 & -0.000003479095533 & 0.000424064149446 \\
-0.000003479095533 & 0.000051367519151 & -0.004018633150428 \\
0.000424064149446 & -0.004018633150428 & 0.550662863570864
\end{array}\right)
$$

To prove condition (15), note that for all cases $A(\alpha)<0, \forall \alpha \in(0,1)$, due to the positiveness of $p_{13}$. Also, it is easy to prove $A(\alpha) \cdot C(\alpha)-{ }_{4}^{1} B^{2}(\alpha)>0$. So, for three cases under study, condition (15) defines a negative quadratic form, and its supremum is negative. Figure 14 represents condition (15) in the three cases ( $\alpha$ from 0 to 1 , by step 0.05 ).

\section{REFERENCES}

1. J. Song and K. Byun, Throttle actuator control system for vehicle traction control, Mechatronics, vol. 9 (5), 1999, pp 477-495.

2. C. Rossi, A. Tilli, and A. Tonielli, Robust control of a throttle body for drive by wire operation of automotive engines, IEEE Transactions on Control Systems Technology, vol. 8, 2000, pp 993-1002.

3. D. Pavkovic, J. Deura, M. Janszb and N. Peric, Adaptive Control of Automotive Electronic Throttle, Control Engineering Practice, vol. 14, 2006, pp 121-136.

4. A. Favela Contreras, I. Perez Quiroz and C. Canudas de Wit, Further Results on Modelling and Identification of an Electronic Throttle Body, in 10th Mediterranean Conference on Control and Automation - MED2002, Lisbon, Portugal, 2002.

5. C. Canudas de Witty, I. Kolmanovsky and J. Sun, Adaptive Pulse Control of Electronic Throttle, in American Control Conference, Arlington, VA, 2001.

6. C. Canudas de Wit, H. Olsson, K. J. Amstrom, and P. Lischinsky, A New Model for Control of Systems with Friction , IEEE Transaction on Automatic Control, vol. 40(3), 1995, pp 419-425.

7. R. Grepl, Adaptive composite control of electronic throttle using local learning method, in IEEE International Symposium on Industrial Electronics (ISIE), Bari, Italy, 2010, pp 58-61. 

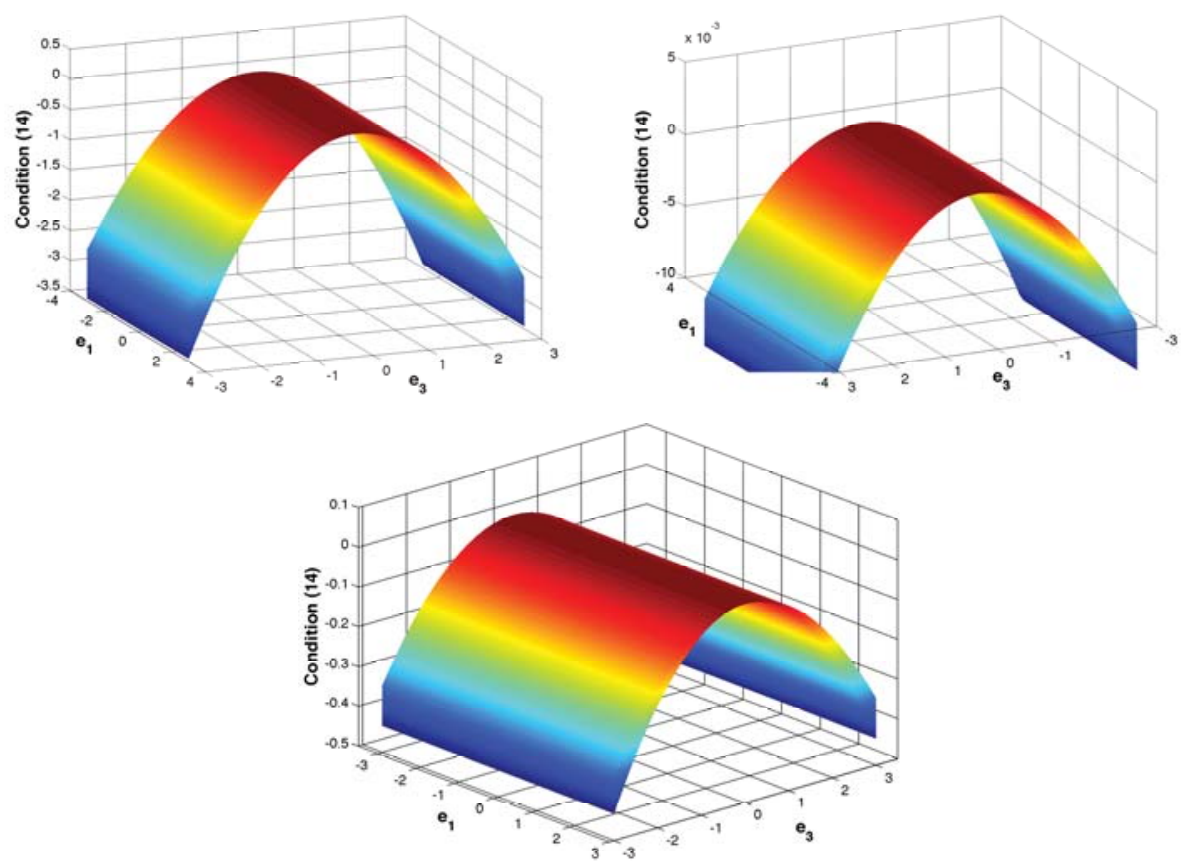

Figure 14. Negativeness of condition (15), for $\alpha \in[0,1]$. From up to down: Case 1, 2 and 3.

8. X. Yuan, Y. Wang, L. Wu, X. Zhang and W. Sun, Neural network based self-learning control strategy for electronic throttle valve, IEEE Transactions on Vehicular Technology, vol. 59 (8), 2010, pp 3757-3765.

9. X. Yuan and Y. Wang, A novel electronic throttle valve controller based on approximate model method, IEEE Transactions on Industrial Electronics, vol. 56(3), 2009, pp 883-890.

10. X. Yuan, Y. Wang, S. Wei and W. Lianghong, RBF networks based adaptive inverse model control system for electronic throttle, IEEE Transactions on Control Systems Technology, vol. 18(3), 2010, pp 750-756.

11. R. N. K. Loh, W.Thanom, J. S. Pyko and A. Lee, Electronic Throttle Control System: Modeling, Identification and Model-Based Control Designs, Engineering, vol. 5, 2013, pp 587-600.

12. A. Kitahara, A. Sato, M. Hoshino, N. Kurihara and S.Shin, LQG Based Electronic Throttle Control with a Two Degree of Freedom Structure, in 35th Conference on Decision and Control, Kobe, Japan,1996.

13. M. Yokoyama, K. Shimizu and N. Okamoto, Application of Sliding Mode Servo Controllers to Electronic Throttle Control, in 35th IEE Conference on Decision and Control, 1998.

14. A. AL-Samarraie and M. Abbas, Design of electronic throttle valve position control system using nonlinear PID controller, International Journal of Computer Applications, vol. 59(15), 2012, pp 27-34.

15. K. Nakano, U. Sawut, K. Higuchi and Y. Okijama, Modelling and observer-based sliding mode control of electronic throttle systems, ECTI trans. on Elec. Eng. Electronics, and Communications, vol. 4(1), 2006, pp 22-28.

16. Y. Vidal, L. Acho and F.Pozo, Robust control of an electronic throttle system via switched chattering control: benchmark experiments, in IFAC Workshop on Engine and Powertrain Control, Simulation and Modeling, Paris, France, 2009.

17. F. Pozo, L. Acho and Y.Vidal, Nonlinear Adaptive Tracking Control of an Electronic Throttle System: Benchmark Experiments, in IFAC Workshop on Engine and Powertrain Control, Simulation and Modeling, Paris, France, 2009.

18. A. Stotsky, B. Egardt and S. Eriksson, Variable structure control of engine idle speed with estimation of unmeasurable disturbances, Journal of Dynamic systems, Measurements and Control, vol. 122, 2000, pp 599-603.

19. R. Garrido and R. Miranda, DC servomechanism parameter identification: A closed loop input error approach, ISA Transactions, vol. 51, 2012, pp 42-29.

20. C.-C Fuh and H.-H Tsai, Adaptive parameter identification of servo control systems with noise and high-frequency uncertainties, Mechanical Systems and Signal Processing, vol. 21, 2007, pp 1437-1451.

21. M. Vasak, M. Baoti, M. Morari, I. Petrovi and N. Peri, Constrained optimal control of an electronic throttle, International Journal of Control, vol. 79(5), 2006, pp 465-478.

22. J.-J.E. Slotine and W. Li, Applied Nonlinear Control, Prentice Hall, Englewood Cliffs, NJ; 1991

23. K. Y. Volyanskyy, W. M. Haddad, and A. J. Calise, A new neuro-adaptive control architecture for nonlinear uncertain dynamical systems: Beyond- and-modifications, IEEE Transaction on Neural Networks, vol. 20 (11), 2010, pp. 1707-1723.

24. T. Yucelen and W. Haddad, Low-Frequency learning and fast adaptation in model reference adaptive control, IEEE Transaction on Automatic Control, vol. 58(4), 2013, pp 1080-1085.

25. S. Bennett, A history of control engineering, 1930-1955, IET. p.p. 48. ISBN 978-0-86341-299-8; 1993

26. R. Toscano, A simple robust PI/PID controller design via numerical optimization approach, J. of Process Control, vol. 15, 2005, pp 81-88. 
27. G. Leena, K. B. Datta and G. Ray, A class of stabilizing PID controllers for position control of single-link manipulator, International Journal of Control and Automation, vol. 4(3), 2011, pp 127-142.

28. Y. G. Wang and H. H. Shao, Optimal tuning for PI controller, Automatica, vol 36, 2000, pp 147-152.

29. X. Yuan and Y. Wang, Neural networks based self-learning PID control of electronic throttle, Nonlinear Dynamics, vol. 55(4), 2009, pp 385-393.

30. A.F. Filippov, Differential equations with discontinuous right-hand sides, Boston: Kluwer Academic, 1988.

31. E. Skafidas, R.J. Evans, A.V. Savkin and I.R Petersen, Stability results for switched controller systems, Automatica, vol. 35, 1999, pp 553-564. 